\title{
CYRENAICAN FUNERARY PORTRAITS IN MALTA
}

\author{
By A. BONANNO \\ (Plates II-III)
}

The Museum Department of Malta possesses among its rich collection of antiquities, both local and foreign, a set of six portraits which should be appended to the remarkable series of Cyrenaican funerary busts studied and published by Miss Elizabeth Rosenbaum. ${ }^{1}$ Four of these busts (I-IV) are exhibited among the sculptures in the 'Roman Villa' Museum at Rabat and the other two (V and VI) are stored in the basement of the National Museum in Valletta. ${ }^{2}$

It is not in the least surprising that Miss Rosenbaum ${ }^{3}$ omitted these busts in her otherwise most comprehensive catalogue of Cyrenaican portraits, which included those scattered in various European collections. The reason for this omission is that these sculptures have either been classified incorrectly or never published. The first to publish four of these portraits (I-IV) was Thomas Ashby, ${ }^{1}$ who gave only a short description of them without attempting a typological classification; he even called one 'a little Phoenician in character's and another 'rather Etruscan-looking': Shortly after, T. Zammit repeated, almost verbatim, Ashby's captions for I, II and IV, while omitting III. ${ }^{7}$

A fuller publication of four of these busts (I-III; V) was made by P. C. Sestieri in a local Maltese periodical. ${ }^{8}$ In his article Sestieri gave an admirable aesthetic appreciation of the four portraits, but he arrived at certain erroneous conclusions. He stated that the three male figures (II, III, V) were in stone and the female one (I) in marble-in reality all four of them are in marble - and he therefore attributed the superior stylistic qualities of the latter to the use of a different material. ${ }^{9}$ Secondly, Sestieri concluded that these portraits are the product of Maltese art, a mixture, he thought, of Punic and Roman elements. ${ }^{10} \mathrm{He}$ made this assumption while admitting that the provenance of the pieces was unknown. ${ }^{11}$ The last portrait (VI) has never yet been published.

When and how these busts found their way to Malta is a question still to be solved. It is highly improbable that they were imported in antiquity since no mention of them is made in the writings on Maltese antiquities, such as those of Abela, ${ }^{12}$ Ciantar, ${ }^{13}$ Houel ${ }^{14}$ and Caruana. ${ }^{15}$ Nor do they seem to have formed part of the sculptures mentioned by Vattier de Bourville's lawyer in his letter to the Louvre authorities, where he speaks of certain pieces of sculpture which, on their way from Cyrene to France, were in transit in Malta. ${ }^{16}$ Smith and Porcher, whose expedition to Cyrenaica started from and ended in Malta, do not mention in their report any sculpture being left in Malta. ${ }^{17}$ From them, however, we know that the local Cyrenaican Bedouin took sculptures to Benghazi to sell them there, ${ }^{18}$ and Maltese merchants or British diplomatic or military officers stationed in Malta could well have brought some of these to the islands. It is probably safe to say that this group of busts was imported into Malta either in the last decades of the nineteenth century or in the early years of this century since, with the Italian occupation of the Libyan

2 E. Rosenbaum, A Catalogue of Cyrenaican Portrait Sculpture (1960) (hereafter Rosenbaum).

I am indebted to the Director and Curator of the Museum Department for providing me with every facility to study, photograph and publish these sculptures.

${ }^{3}$ Now Mrs. Alföldi.

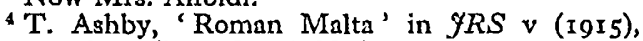
77, nos. 8-II (hereafter Ashby).

${ }^{5}$ ibid. 77 , no. II.

- ibid. 77 , no. 8.

7 T. Zammit, Guide to the Valletta Museum (19r9), 25 (hereafter Zammit).

B P. C. Sestieri, 'Sculture Maltesi II', Archivio Storico di Malta x (1939), 231-8 (hereafter Sestieri).

$\checkmark$ ibid. 233.

10 ibid. 238

12 ibid. 232, n. 3.

$12 \mathrm{G}$. F. Abela, Della descrittione di Malta isola nel mare siciliano, con le sue antichitd, ed altre notitie, libri quattro ( 1647 ).
${ }^{13}$ G. F. Abela-G. A. Ciantar, Malta Illustrata (I772-80).

${ }_{14} \mathrm{~J}$. Houel, Voyage pittoresque des isles de Sicile, Lipari et Malte (1782-7).

${ }_{15}$ A. A. Caruana, Report on the Phoenician and Roman Antiquities in the group of the islands of Malta (1882).

${ }^{10}$ On Vattier de Bourville and his correspondence, see Rosenbaum, I-2.

17 Captain R. Murdoch Smith, R.E., and Commander E. A. Porcher, R.N., History of the Recent Discoveries at Cyrene made during an Expedition to the Cyrenaica in I860-6I (I864). They only say (84) that the sculpture collected was transferred from one ship to another in Malta and 'soon afterwards safely conveyed to England'.

2B Smith and Porcher, op. cit. I6, speak of an old Arab who spent his time digging in the ancient necropolis in Benghazi and used to sell his finds to Maltese merchants in the town. 
territory in 1912 , the trade in archaeological material virtually stopped. Furthermore, the Reports of the Museum Department of Malta often mentioned Cyrenaican objects and marble sculpture donated to the Museum by private persons. ${ }^{10}$

This group of six busts belongs to a very standard type of portrait produced in Cyrenaica: the funerary busts which the inhabitants of this Roman province set up on their tombs. ${ }^{20}$ These portraits, the majority of which were found in Cyrene, display a number of typical, easily identifiable characteristics which distinguish them from any other class of portraits, and the six busts preserved in Malta show all these characteristics. The most important of these is the shape, namely a bust worked out on the front, almost in relief, with two flat strips running vertically along the neck from the ears to the shoulders which give the impression of a veil falling down from the henad. Some facial features which have been defined as 'Libyan',21 such as the high cheek-bones and the shape of the mouth and eyes, are typical of most, if not all, of these portraits. Finally, the sculptural technique, especially the lack of the use of the drill and the absence of incised irises and drilled pupils in busts datable to the second century A.D. and later, is also an unusual feature.

Funerary portraiture was introduced in Cyrenaica after the latter became a Roman province in 75 B.C. Before, funerary sculpture, particularly in the city of Cyrene, was represented by veiled female busts with standard facial features or, often, without a face altogether. ${ }^{22}$ It was after 75 B.C. that the Romans brought with them into this former Greek colony their funerary tradition of representing the portrait features of the dead in sculpture to be placed on or near the tomb. The Cyrenaicans adopted this tradition probably as early as the second half of the first century B.C. and continued to practise it right up to the age of Constantine. ${ }^{23}$ However, instead of carving busts in relief on flat slabs, as the Romans did in the capital, the Cyrenaicans produced individual, detached busts which they inserted in small niches gouged out of the façades of their rock-cut tombs. That their inspiration was ultimately derived from the Roman funerary relief portrait is confirmed by the fact that the Cyrenaican busts are completely flat at the back and when set against a plain background they give the impression of being cut in relief.

\section{Catalogue}

I Bust of a woman (Pl. II, x). Rabat, Museum. Inv. $54{ }^{24}$ Ashby 77, no. 10; Zamamit 25; Sestieri 23I-8. Provenance not recorded. Medium-grained white marble. H. total $0.20 \mathrm{~m}$; head $0 \cdot$ I 5 m. Nose, upper lip and part of the lower lip chipped. Marble discoloured to a red sandstone colour.

The bust is draped and flat at the bottom. The drapery apparently consists of a light tunic, visible on the chest, over which a mantle is worn.

The portrait shows a woman of rather mature age. Her hair is parted in the centre and drawn back to the sides in regular wavy strands covering the upper part of the ears. The crown of the head is covered by a veil with folds crossing in front. The eyes are set well apart and have strongly curved upper lids and straight lower lids. Her face is rather angular with extremely high cheeks and pronounced chin and jaws.

II Bust of a man (P1. II, 2). Rabat, Museum. Inv. 55. Ashby 77, no. II; Zammit 25; Sestieri 23I-8. Provenance unknown. Medium-grained white marble. H. total $0.19 \mathrm{~m}$; head $0.13 \mathrm{~m}$. The right ear knocked off. Surface worn in various parts and discoloured to a red sandstone colour.

The bust is draped and straight at the bottom.

The portrait is that of a man in his early manhood. 'The face, square shaped, has a very

10 In fact two of these funerary busts were donated to the Department in the first decade of this century. Annual Report for the Museum Department, ipo6-7, p. E I; ro08-0, p. E r.

20 See Rosenbaum $13-28$, IOI-23; nos. $185^{-28} 3$, 299-3 18 , pls. LXXIX-C, CV. Until Rosenbaum's publication these funerary portraits seem to have escaped the attention of archaeologists completely. In fact only one such portrait had been published, in 1933 by $\mathrm{S}$. Ferri, in order to illustrate the difference between Roman Art in a northern province (Pannonia) and that in a former Greek colony-S. Ferri, L'arte romana sul Danubio (1933), 137-8, fig. 160 .

${ }^{21}$ Rosenbaum $2 \mathrm{r}-3$.

22 For an example see $E A A$ ii (1959), fig. 002 ; cf. now L. Beschi, 'Divinita funerarie cirenaiche', ASAtene xxxi-ii (1060-70), 132-341.

${ }^{23}$ Rosenbaum 26 ff.

2s There is still no inventory of the Classical sculpture in the Maltese national collections. The numbers appearing here are those marked on the bases of the busts. 
broad but low forehead, high cheek-bones and prominent chin. The hair is brushed forward on to the forehead and sideways towards the temples in fairly regular and slightly wavy locks. A pair of long whiskers descend to the neck in small shallow locks. The almond-shaped eyes are set well apart with the upper lids much more curved than the lower ones. These somatic features, together with that of the upturned corners of the mouth, are very representative of what Rosenbaum termed Libyan ethnic characteristics.

III Bust of a young man (PI. IY, 3). Rabat, Museum. Inv. 5I. Ashby 77, no. 8; Sestieri 23I-8. Provenance unknown. Medium-grained white marble. H. total $0.20 \mathrm{~m}$; head $0.14 \mathrm{~m}$. Tip of nose broken off. Other chips. Surface corroded in parts and discoloured to a reddish shade.

In this case a young man is represented with very ugly and unorganic features. The head, broad and squarish, is planted on a wide massive neck. Eyes, almond-shaped and set wide apart, small mouth, ears placed too high up the sides of the head, the right one being considerably higher than the left one. The hair frames the forehead and temples with an arched fringe formed by shallow curved locks.

IV Bust of a man (Pl. II, 4). Rabat, Museum. No number. Ashby 77, no. 9; Zammit 25. Provenance not recorded. Coarse-grained white marble. H. total $0.26 \mathrm{~m}$; head $0.14 \mathrm{~m}$. A large piece broken off on the lower left side. Chips on nose, lips and chin. Surface corroded in various parts and discoloured to a greyish shade.

This is the only bust with rounded undraped lower part, but it presents the usual flat surfaces along the neck.

The face is rather rectangular in shape, slightly rounded at the full chceks. The hair, arranged in regular series of short spiral curls (of which only the foremost two are indicated), frames the forehead and temples with a shallow arch. The eyes are of the usual type but this time wide open and slanting downwards towards the nose. The ears are far too big and very schematically shaped.

$\mathrm{V}$ Bust of an old man (Pl. III, I and 2). Valletta, basement of National Museum. Inv. 53. Sestieri 231-8. Provenance not recorded. Coarse-grained white marble. H. total $0.4 \mathrm{r} \mathrm{m}$; head $0.21 \mathrm{~m}$. Lower left corner broken off. Tip of nose missing. Surface corroded and discoloured to a red sandstone colour.

The bust includes a good part of the chest and the shoulders; it is draped and flat at the bottom. The side strips are broad and start from above the ears.

We have here a portrait of an old man with a very lean and emaciated face. The eyes are deep-set with heavy upper lids which are barely visible due to the corrosion of the marble. The forehead is low and narrow, arched by the hair which is combed forward in regular series of schematic locks, leaving the ears entirely visible. Of the hair only the foremost two layers are indicated, behind which one notes only rough chiselling. The high cheek-bones and the protruding chin emphasize the hollowness of the cheeks.

The bust is carved from another piece of sculpture. On the teverse one can easily make out the shape of the back of a nude torso (PI. III, 2). The torso is partially covered by a cloak which is carried on the left shoulder. It must have belonged to a figure with long hair, four tresses of which are still visible on the right.

VI Bust of a woman (Pl. III, 3 and 4). Valletta, basement of National Museum. No number. Donated by Madam A. Alvarez in 5936 . Unpublished. Fairly coarse-grained white marble. H. total $0.53 \mathrm{~m}$; head $0.27 \mathrm{~m}$. Bust restored from two pieces, line of break running across the neck and shoulders. Otherwise in very good condition. Two square holes $(3 \mathrm{~cm} \mathrm{x} 3 \mathrm{~cm})$ on the left side.

The bust includes a considerable part of the chest and presents the usual plain strips; it is flat at the bottom and draped. The portrait is that of a middle-aged woman with rather hard facial features. The hair is parted in the centre and arranged in regular waves with high crests, combed down to the sides and back leaving only the ear-lobes visible. On top is a high cone formed of thin plaits arranged in horizontal layers.

The face is almost oval but the planes of the forehead, pronounced cheek-bones and chin meet at sharp angles and a certain hardness is imparted to the face, giving it a serious expression. The eyes are almond-shaped with rather deep grooves separating the upper lids from the brows. The nose is aquiline; the mouth small with closed lips. The lady is 
wearing a tunic and a mantle which covers both shoulders and is laid crosswise over the chest in a kind of roll.

The first three of these busts seem to form a homogeneous group; they are carved out of the same type of marble and have exactly the same dimensions, shape and drapery. The treatment of the eyes and mouth is similar in all three portraits, and a certain asymmetry in the face links II and III the more closely. Indeed we are tempted to suggest that this group was produced in the same workshop; but we dare not go so far as to suggest, as Sestieri did, ${ }^{25}$ that they are the work of a single craftsman, because of the great differences in style and skill. These three busts form quite an independent group even within this class of portraiture, and the only Cyrenaican bust which, at first sight, seems to be very similar to them is no. 256.26 However, after examining the bust itself, which is housed in the basement of the British Museum, I found that the head is smaller, much flatter, and executed in a totally different style.

The head of female portrait $I$ is rendered very naturalistically but assumes a rather geometrical construction. The carver was evidently influenced by contemporary Roman official portraiture inspired by neo-Classical ideals, though he did not neglect certain personal features, such as the leanness of the cheeks and the upturned corners of the mouth. The modelling is rather hard and dry but a slight colouring effect is noticeable around the cheeks and in the shadows of the deep-set eyes.

The style of the portrait and the formation of the hair assign this sculpture to the Julio-Claudian period, as Sestieri rightly suggested. The hairstyle in fact is identical, with slight variations, to that in most female portraits of the Julio-Claudian period. ${ }^{27}$ As for the Cyrenaican funerary portraits, the best comparisons can be made with no. 207 for the treatment of the facial features, ${ }^{28}$ and with nos. 248 and 256 for the lower part of the bust and its general shape. ${ }^{29}$

The second portrait belongs probably to the same period, that is around the middle of the first century A.D. The squareish construction of the head and the shape of the eyes find analogies in nos. 232-6 of their Cyrenaican counterparts, ${ }^{30}$ while the hairstyle brings it closer to nos. $192-4{ }^{31}$ This particular hairstyle, with the tips of the foremost locks pointing in opposite directions from the centre of the forehead, is found in many portraits of the Julio-Claudian princes-cf., for instance, the portrait of young Tiberius (?) in the Lateran collection ${ }^{32}$ and that of Caligula (?) in the Museo Nazionale in Rome. ${ }^{33}$ The long whiskers, on the other hand, hardly suggested by incised lines, recall more closely the heads of Nero, one in the Museo Nazionale, ${ }^{34}$ the other in the Vatican Museum. ${ }^{35}$

Portrait III is very primitively executed and lacks artistic qualities. The shallow and unrealistic treatment and the complete asymmetry of the face, together with the inexpressive stare of the eyes, reveal the craftsman's lack of skill. The hairstyle seems to date this head also to the Julio-Claudian period. ${ }^{36}$ Similar hairstyles are worn by nos. $192-4$ of the Cyrenaican funerary portraits assigned by Rosenbaum to the period of Nero. ${ }^{37}$

The shape of the bust has been considered by Rosenbaum to be of primary importance as a dating criterion in Cyrenaican funerary portraiture. For the flat-bottomed draped type she has in fact established a terminus post quem which cannot, however, be accepted after examination of the previous three busts (I-III) as well as V. Since these are obviously draped and flat at the bottom, and since they are all datable to approximately the second half of the first century, the argument ex silentio, that 'it never occurs before the time of Hadrian ', 38 should no longer be considered applicable.

In imperial portraiture this type of bust, including the shoulders and part of the chest,

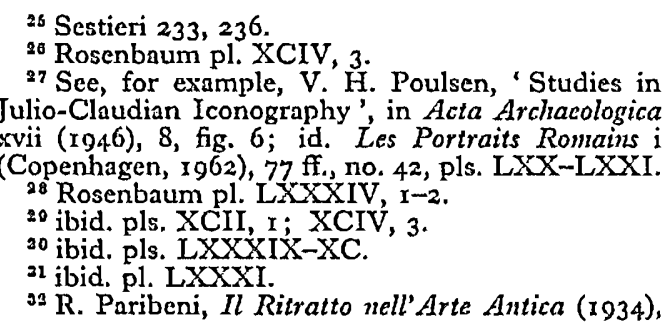

pl. CXXXII; A. Giuliano, Catalogo dei Ritratti

Romani del Musco Profano Lateranense (1957), pl. 10. ${ }^{3}$ B. M. Felletti Maj, Museo Nazionale Romano. I Ritratti (1953), no. 108.

s4 A. Hekler, Bildniskunst d. Griechen u. Römer (ror ), pl. 183 .

${ }^{35}$ Paribeni op. cit. (n. 32), pl. CLV.

${ }^{36}$ See previous portrait and $\mathrm{nn} .32-5$.

3 Rosenbaum r03, pl. LXXXI.

38 ibid. 19. 
appears for the first time in the Decennalia portraits of Trajan, created in $108 .^{30}$ In privately sponsored sculpture in Rome it also appears on the funerary monument of the Haterii, dated to the first decade of the second century A.D. $10 \mathrm{It}$ is, indeed, on this monument that the whole idea behind these Cyrenaican portraits is best exemplified, namely, a bust sculptured in very high relief against a flat wall in a niche which vaguely recalls the little cupboards in which patrician families kept their ancestral images.

No. IV, on the other hand, is typical of the rounded bust and has close parallels, even for hairstyle, in a number of Cyrenaican portraits dated to the period of Nero. ${ }^{41}$ From the imperial portraits a pertinent comparison can be made with the head of Titus of the Atrio dei Quattro Cancelli in the Vatican, ${ }^{42}$ and the colossal bust of the same emperor in Naples. ${ }^{43}$ The portrait may, therefore, be dated to the Neronian or Flavian periods.

This bust adds considerably to the importance and interest of the collection since it is produced from another piece of sculpture, namely from the head of an archaic kouros. The stereometric construction of the head, the schematic arrangement of the hair, and the stylized treatment of the ears reveal the previous identity of this sculpture. There are other Cyrenaican busts carved from archaic kouros heads ${ }^{44}$ and they deserve a separate study collectively.

Another unique piece is no. $V$. While the face is a perfect document of the lateRepublican 'death-mask' tradition, the hair-style does not admit a date prior to the Neronian or Flavian period. In Roman sculpture the nearest parallels, as regards their extreme realistic content, are to be found in funerary reliefs, ${ }^{45}$ and in many Republican ${ }^{\text {is }}$ and, to some extent, even in Flavian portraits. ${ }^{47}$ However, the bust must be dated to the second half of the first century A.D. or the Trajanic period, at the latest, on account of the hairstyle which, with its clearly separated layers of locks upon the forehead, occurs only during this period. ${ }^{48}$ This date further confirms our conclusion as to the chronology of the flat type of bust. From the artistic point of view, it is difficult to say how far the sculptor is responsible for the successful rendering of this extremely realistic portrait. Certainly its realism, rather than concentrating on the superficial abnormalities of the skin, as in many Republican portraits, suggests the bone structure of the face.

This bust is also carved from another sculpture, this time from the front of a nude torso (PI. III, 2).

The last portrait (VI) is also the latest of our group and, together with the other female portrait (I), is the most naturalistically rendered and perhaps the most successful portrait of the six as far as finishing and technique are concerned. The surfaces of the face have been nicely smoothed and great care has been lavished on the details of the hair. One must further note the absence of the incised irises and drilled pupils in the eyes, and the lack of drill-work in the treatment of the hair, otherwise so typical of contemporary marble portraiture. The coiffure suggests a date in the early Antonine period. In fact it is a variant of the style of Faustina the Elder ${ }^{49}$ and identical with the one worn by the bust from Cyrene in the British Museum, no. $1416 .^{50}$ Of the other Cyrenaican portraits compare nos. 249, 255,257 and 259 .

Once again the block of marble from which this portrait is carved seems to have been re-employed. This time the block was an architectural fragment, as is suggested by the square holes on the right side of the bust (Pl. III, 4). The re-employment of architectural elements is also very common among Cyrenaican funerary portraits. ${ }^{51}$

This wide use of previously worked marble may explain to some extent why all the

${ }^{20} \mathrm{~W}$. H. Gross, Bildnisse Trajans (1940), 85-98; B. M. Felletti Maj, s.v. 'Traiano' in $E A A$ vii (1966), 963-5.

io $\mathrm{F}$. Poulsen, Catalogue of Ancient Sculpture in the Ny Carlsberg Glyptotek (195); R. Bianchi Bandinelli, Rome: The Centre of Power (1970), fig. 244; Giuliano op. cit. $(n, 32)$ nos. $5 x-2$, however, dates the portraits to the Trajanic or early Hadrianic period.

${ }^{41}$ Rosenbaum nos. I 86-90, pls. LXXIX-LXXX.

42 G. Lippold, Die Sktlpturen des Vaticanischen Museums (1936-56), iii 2 , pl. $x_{4}$, no. 4.

${ }^{\triangleleft a} \mathrm{M}$. Wegner, Das Römische Herrsclerbild, Die Flavier (1966), pl. I4 $\mathrm{a}-\mathrm{b}$.
44 Such as nos. $188-90$.

${ }^{45}$ See V. Poulsen, Les Portraits Romains i, no. Ir4, pl. CLXXXIX; Giuliano, op. cit. (n. 32), pl. I, 2a; pl. II, $2 \mathrm{~b}$.

46 Bianchi Bandinelli, op. cit. (n. 40) fig. 92.

\$7 Felletti Maj, op. cit. (n. 33) no. 145 .

4 See, for example, Felletti Maj, op. cit. (n. 33), no. $130 ; \mathrm{H}$. Stuart Jones, The Sculptures of the Palazzo dei Conservatori (1926), 65, pl. 16.

${ }^{40}$ Lippold, op. cit. (n. 42), iii $x$, no. 570, pl. 63.

"Rosenbaum no. 58, pl, XXXVIII, 2-4.

$" 1$ See ibid, nos. $251,255,282$. 
Cyrenaican funerary busts are made of marble. The portraits were apparently commissioned by members of a lower middle-class - as the number of pieces discovered and their artistic quality suggest-and the importation of marble would have been too costly for them to afford. The marble, therefore, must have been imported from Greece and the islands, ${ }^{52}$ and used in earlier times when Cyrene was a rich and flourishing Greek colony. When its prosperity declined and it came under Roman rule, the craftsmen working in these workshops found plenty of scrap material to work on. In most cases they took care to leave no trace of previous work, in others they did not bother to finish them off.

Considering the organic and naturalistic style of most funerary portraits from Cyrenaica, one is inclined to assume that the earlier Greek sculptural tradition came to the aid of the carvers of these portraits, so as to overcome a certain abstract and simplified representation of the human face which characterizes most Roman provincial art, and which survived even on Italian soil at a comparatively late date, as in numerous cippi from the Roman necropolis at Tarentum. ${ }^{53}$ In a province so distant from the imperial capital, this naturalistic rendering of portraits commissioned not by a restricted élite but, presumably, by a less well-off middle-class, can be explained only in the light of a strong Greek tradition which persisted among the Cyrenaican craftsmen in Roman times. This is well illustrated by the two female portraits (I and VI), rather less so by the male busts II and IV. V belongs completely to the more closely Roman tradition, whereas III is the only portrait that shows a certain abstract simplicity which is due more to the inability of the sculptor than to the expression of any other tradition-such as the Punic one proposed by Sestieri. ${ }^{54}$

Another strong influence in this direction might have come from the East, that is from contemporary Egyptian portraiture both sculptural and pictorial, which had itself a strong Hellenistic background and, before that, a stronger tradition in ancient Egyptian art. That Egyptian art exerted a great influence on the Cyrenaican funerary portraits, at least from the iconographic point of view, is in fact clearly demonstrated in Rosenbaum's introduction. ${ }^{55}$

\section{Royal University of Malta}

\footnotetext{
"No marble is found in Cyrenaica itself. See Rosenbaum 5 .

${ }^{63}$ Bianchi Bandinelli, op. cit. (n. 40), 74, fig. 82;
}

id. s.v. 'Ritratto' in $E A A$ vi (1965), fig. 822 ;

P. Pensabene, Röm. Mitt. Ixoxii (I975), $263 \mathrm{ff}$.

${ }^{54}$ Sestieri 232,238 . 


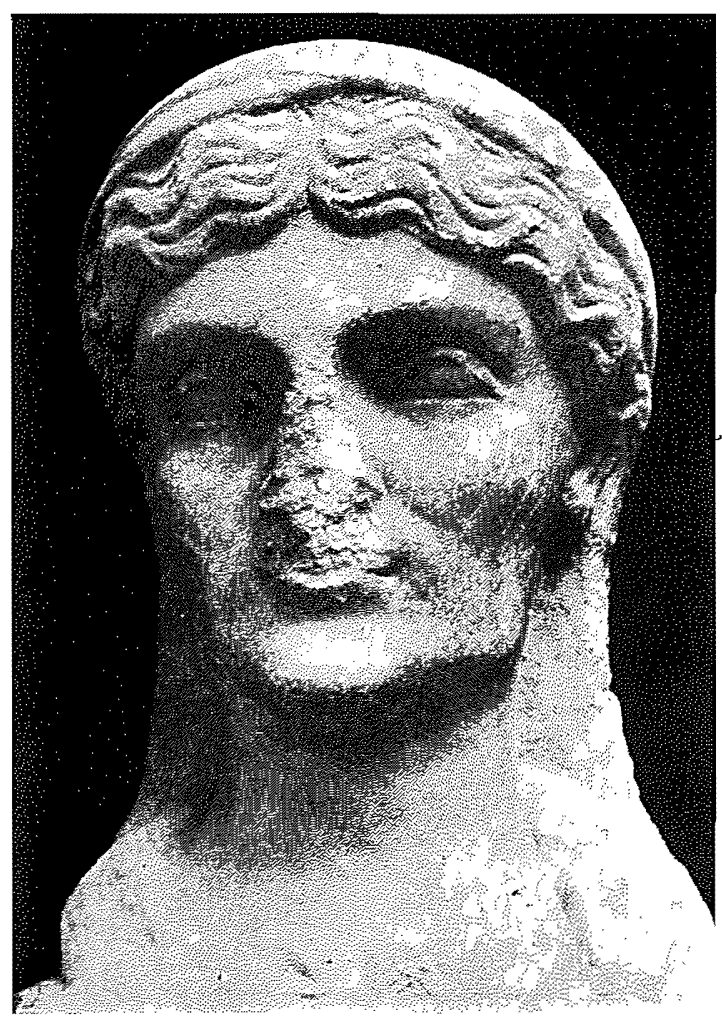

(r) Cat. no. I

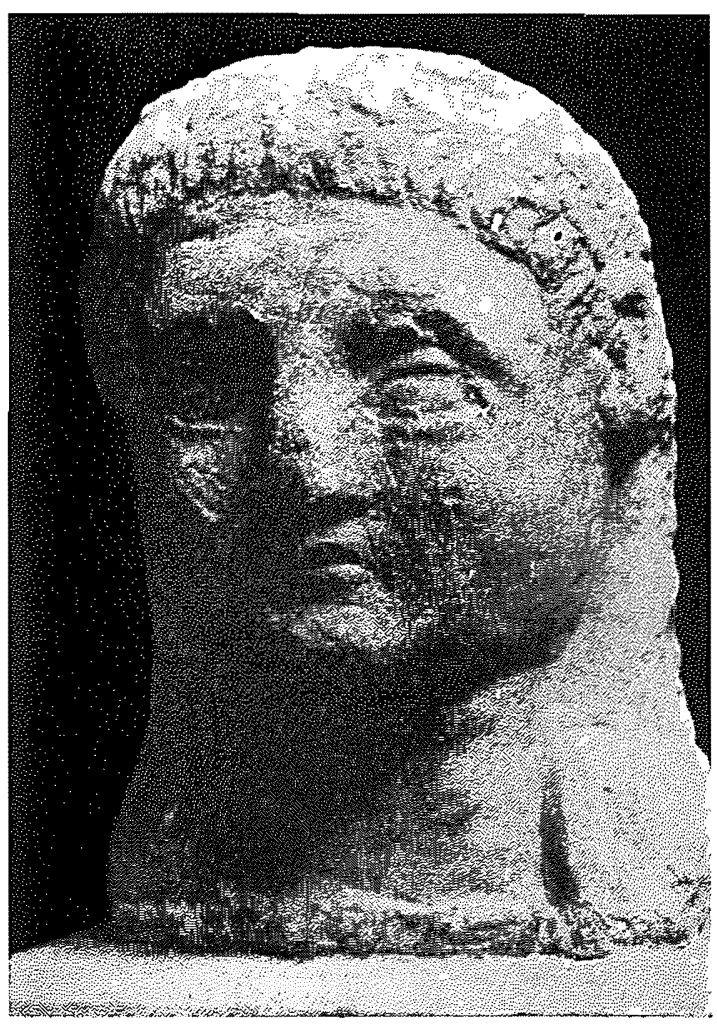

(3) Cat. no. III

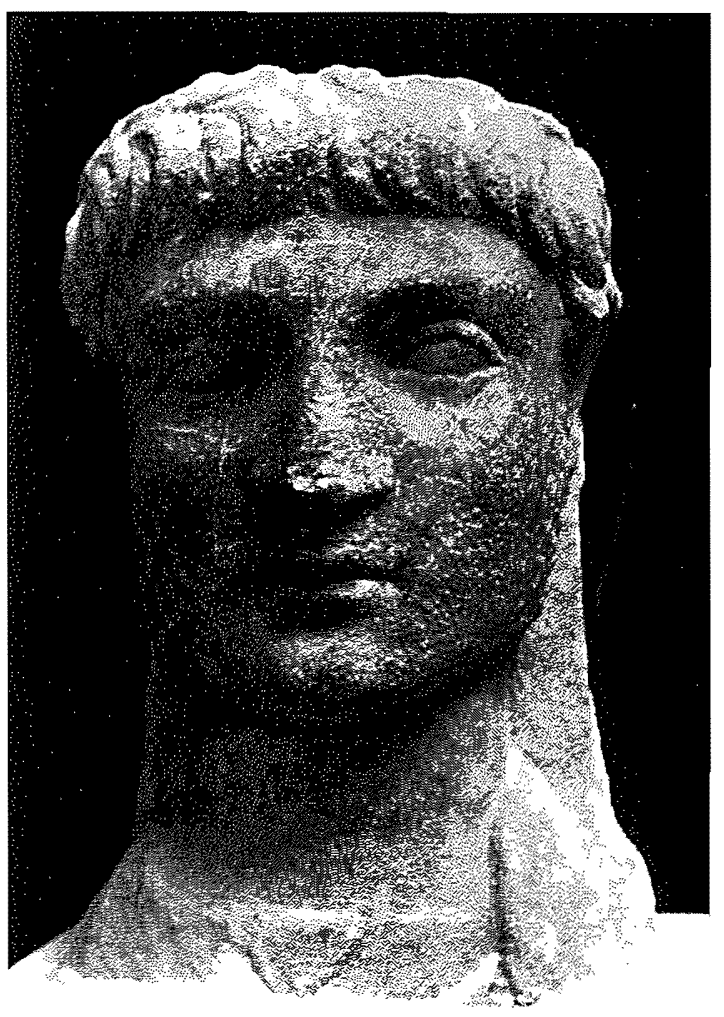

(2) Cat. no. II

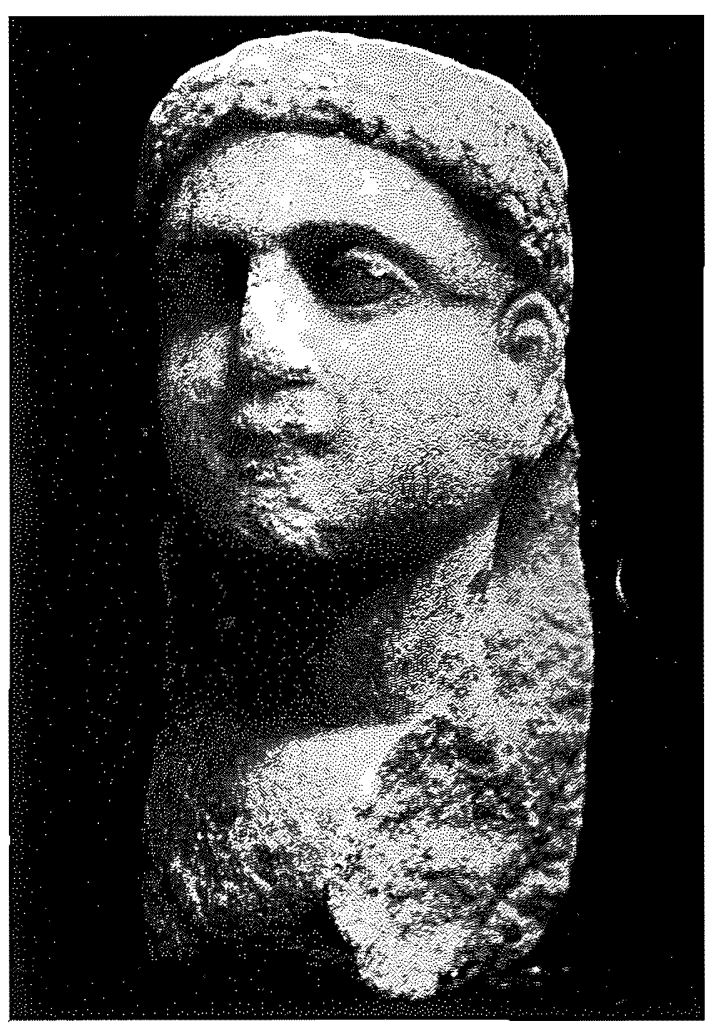

(4) Cat. no. IV

CYRENAICAN FUNERARY PORTRAITS IN MALTA (see pp. 39-44)

Photographs by $A$. Bonanno. Copyright reserved 


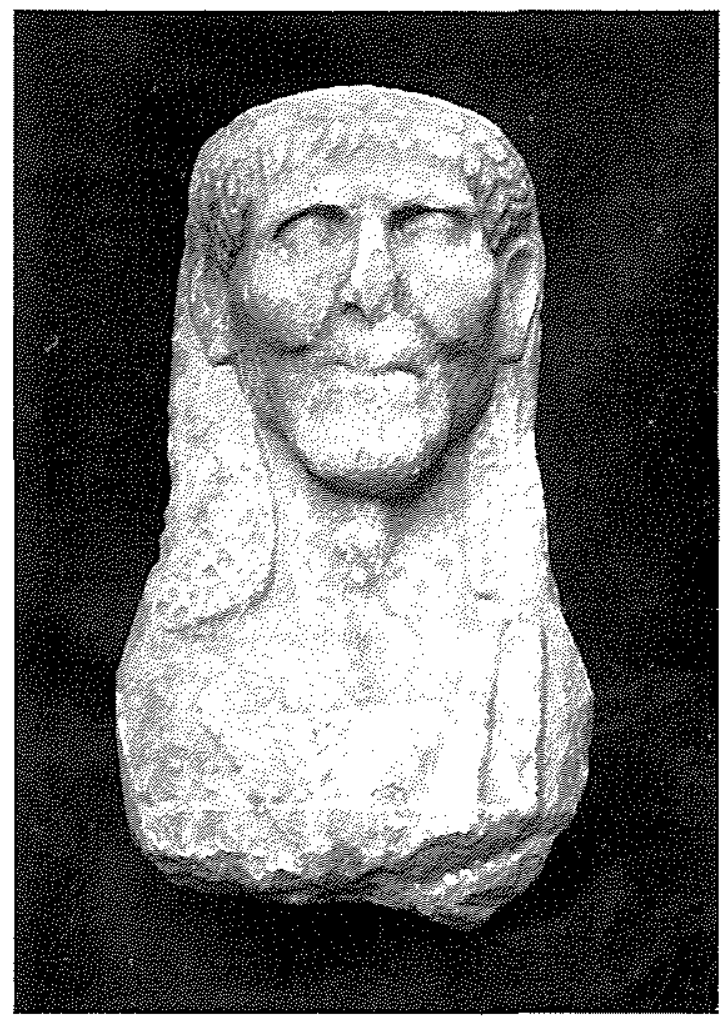

(I) Cat. no. V.

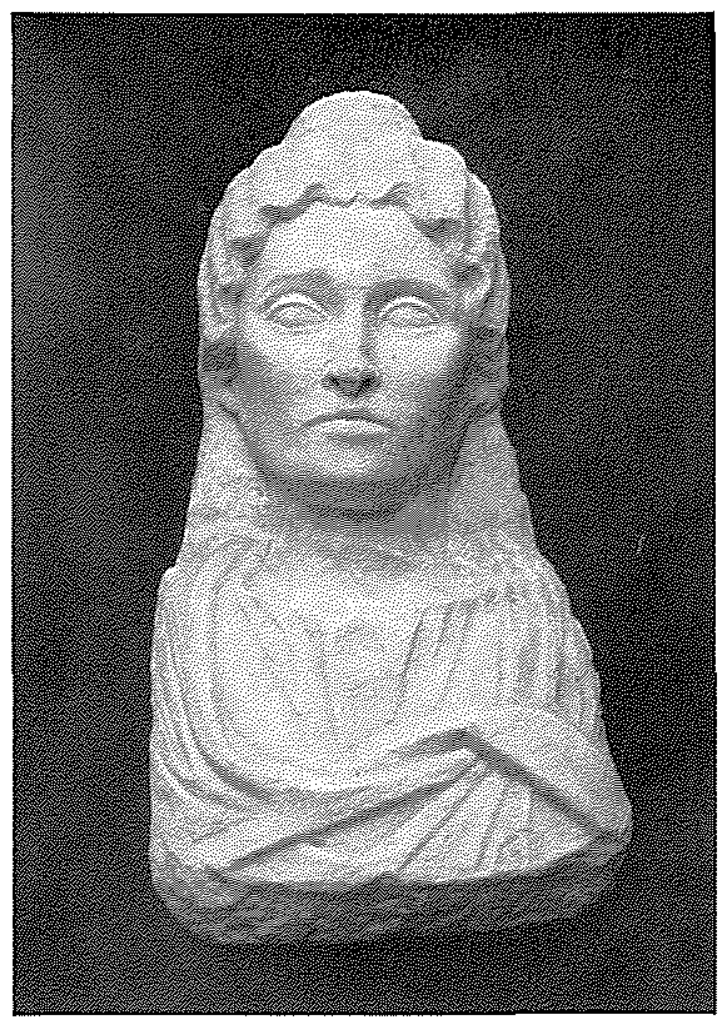

(3) Cat. no. VI

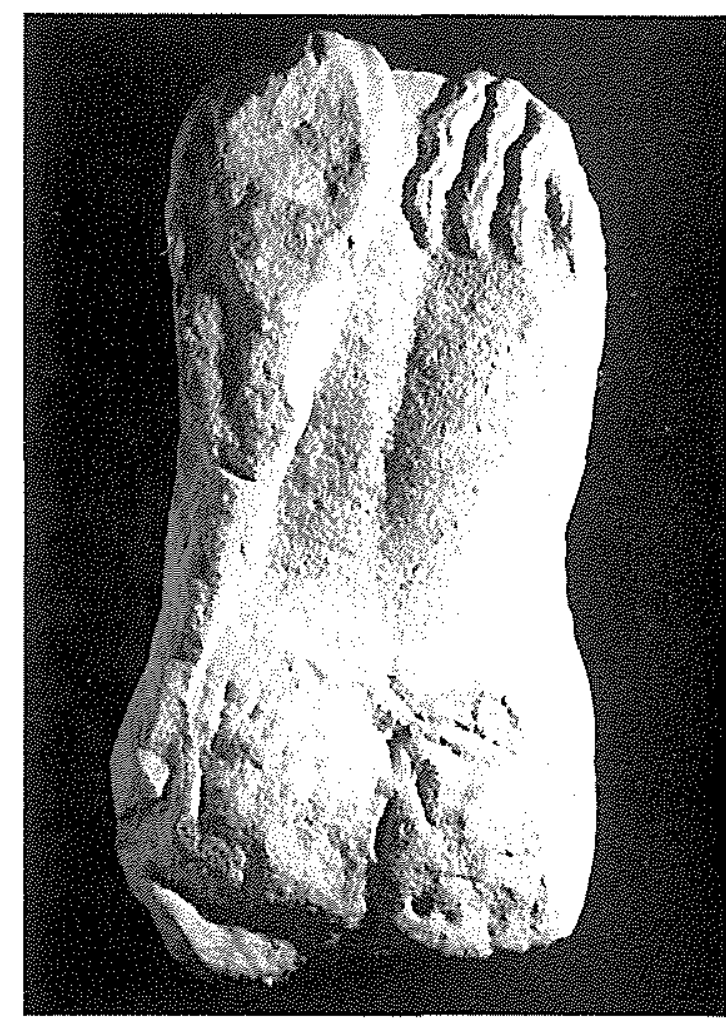

(2) Cat. no. V

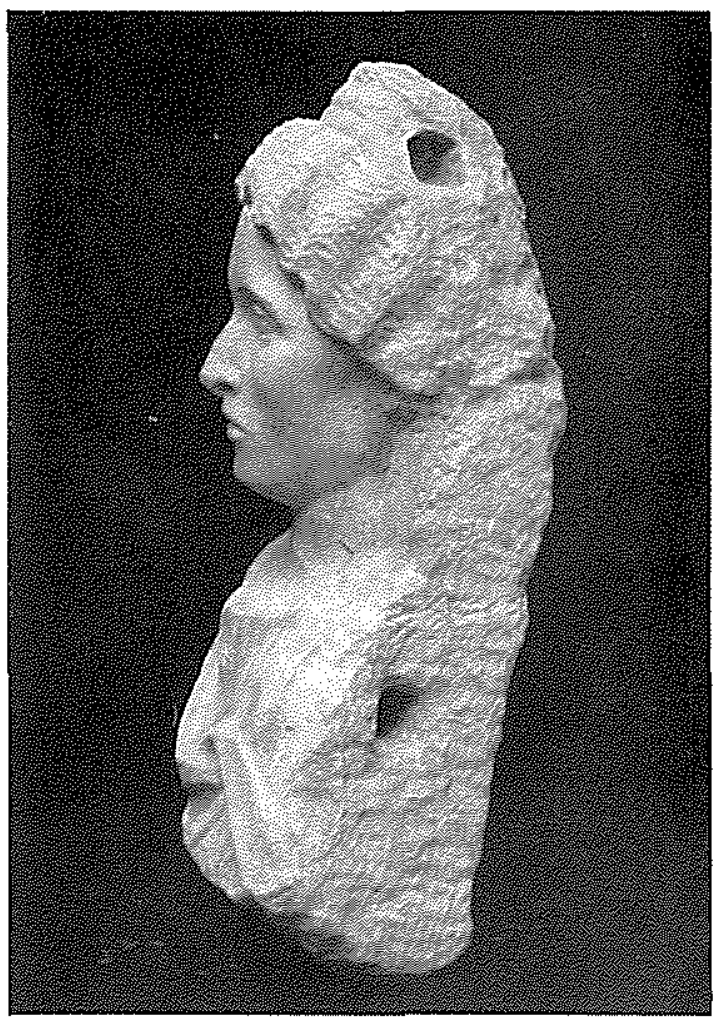

(4) Cat. no. VI

CYRENAICAN FUNERARY PORTRATS IN MALTA (see pp. 39-44) Photographs by A. Bonanno. Copyright reserved 